\title{
Mechanical Evaluation of Effect of Grape Seed Proanthocyanidins Extract on Debilitated Mandibles in Rats
}

\author{
Masaru GUNJIMA, Iwan TOFANI, Yukimi KOJIMA, Kenshi MAKI and Mitsutaka KIMURA \\ Department of Pediatric Dentistry, Kyushu Dental College 2-6-1, Manazuru, Kokurakita, Kitakyushu 803-8580, Japan \\ Corresponding author, E-mail:k-maki@kyu-dent.ac.jp
}

Received October 30, 2003/Accepted March 19, 2004

\begin{abstract}
Grape seed proanthocyanidins extract (GSPE), whose principal ingredient is proanthocyanidins, shows many activities such as cholesterol lowering effects, antioxidant effects, anti-tumor effects, cardioprotective effects, and protection against ultraviolet rays. However, reports of the effects of GSPE on bone are rare. We performed a mechanical analysis of the effect of GSPE on the interior structure of rat mandibular bone in the growth period, using three-dimensional peripheral quantitative computed tomography (pQCT). A low-calcium /high-calcium diet with supplementary GSPE was compared to a lowcalcium/high-calcium diet in rats with debilitated mandibular bones. The group who received added GSPE showed a significant increase in cortical bone density, cross-sectional area, and trabecular bone mineral content $(p<0.05)$. A significant increase was also seen in the results of a non-invasive stress strain index (SSI) $(p<0.01)$ in the added GSPE. Our findings suggest that GSPE can increase bone quality and bone strength of rat mandibles in the growth period.
\end{abstract}

Key words: GSPE, pQCT, Rat mandible

\section{INTRODUCTION}

The peak development of bone mass occurs in the growth and building period from infancy to adolescence, and is a major determinant of bone mass later in life. During this period, insufficient calcium causes debilitated bone, which results in a failure to reach peak bone mass. Thereafter, bone mass decreases with aging and calcium has an influence on the prevention and prognosis of osteoporosis. In conventional therapy, high-calcium supplementation is used to treat debilitated bone ${ }^{1-4)}$, however, sufficient bone mass in debilitated bone can not be achieved by added calcium alone. Grape seed proanthocyanidins extract (GSPE) is a flavonoid derivative with proanthocyanidins as the principal ingredient. Ipriflavone, which participates in the calcification of bone and has been used to inhibit bone resorp$\operatorname{tion}^{5-9)}$, has been reported to belong to the same flavonoid group. GSPE is known to have many activities, such as a cholesterol lowering effect ${ }^{10)}$, a cytotoxic effect on human cancer cells ${ }^{11)}$, cardioprotective properties ${ }^{12)}$, stimulation of angiogenesis in dermal wound healing ${ }^{13)}$, and protection against ultraviolet rays $^{14)}$. However, there have been few reports of its effects on bone metabolism, especially in the growth period. In the present study, we performed mechanical analysis of experimentally debilitated mandibular bones in rats to investigate the effect of GSPE with a high-calcium (UNICAL ${ }^{\circledR}$ ) $\operatorname{diet}^{15)}$ using three-dimensional peripheral quantitative computed tomography (pQCT) to separately measure trabecular and cortical bone, bone density, mineral content, cross-sectional area, and non-invasive bone strength (with a stress strain index, SSI).

\section{MATERIALS AND METHODS}

\section{Animals and treatments}

Forty 5-weeks-old male Wistar rats, each weighing about $115 \mathrm{~g}$, were used. They were divided at random into 4 groups and housed in small cages individually under similar conditions at $22 \pm 1^{\circ} \mathrm{C}$ with a 12-hour illumination time $(8: 00$ am to $8: 00 \mathrm{pm})$. Group A rats were fed a standard diet (Oriental Combination A diet, Oriental Yeast) and given tap water freely for 6 weeks. Group B rats were given the low-calcium diet (Oriental Combination A variant diet, calcium content $30 \%$ of Oriental Combination A diet) and distilled water for 6 weeks. Group $\mathrm{C}$ rats were fed the low-calcium diet and given distilled water for 3 weeks, and then a high-calcium diet (74\% Oriental Combination A diet, 26\% UNICAL) with distilled water for 3 weeks. Group D rats were given the low-calcium diet and distilled water for 3 weeks, and then the same high-calcium diet as in Group C, along with supplementary $0.003 \%$ GSPE (TOKIWA PHYTOCHEMICAL CO., LTD) and distilled water for 3 weeks. The components of the individual diets are presented in Tables $1 \sim 3$. Following the 6-week experimental period, all rats were killed with thiopental sodium (Ravonal ( $\mathrm{r}$ ) ; Tanabe Seiyaku CO., LTD) under deep anesthesia with diethyl ether. The mandibles were immediately removed and fixed in 10\% neutral buffered formalin. All procedures were approved by the Committee for the Use and Care of Laboratory Animals of Kyushu Dental College, Japan. 
Table 1 Composition of all diets

Table 2 Mineral mixture of standard diet and low-calcium diet

\begin{tabular}{|c|c|c|}
\hline Ingredients & Standard diet & Low-calcium diet \\
\hline Ca-lactate & 35.09 & - \\
\hline $\mathrm{KH}_{2} \mathrm{PO}_{4}$ & 25.72 & 28.33 \\
\hline $\mathrm{CaHPO}_{4} \cdot 2 \mathrm{H}_{2} \mathrm{O}$ & 14.56 & - \\
\hline $\mathrm{K}_{2} \mathrm{HPO}_{4}$ & - & 9.55 \\
\hline $\mathrm{NaH}_{2} \mathrm{PO}_{4}$ & 9.35 & 9.38 \\
\hline $\mathrm{MgSO}_{4}$ & 7.17 & 7.18 \\
\hline $\mathrm{NaCl}$ & 4.66 & 4.68 \\
\hline Fe-citrate & 3.18 & 3.19 \\
\hline $\mathrm{MnSO}_{4} \cdot 4 \sim 5 \mathrm{H}_{2} \mathrm{O}$ & 0.12 & 0.13 \\
\hline $\mathrm{ZnCO}_{3}$ & 0.11 & - \\
\hline $\mathrm{ZnCl}_{2}$ & - & 0.10 \\
\hline $\mathrm{CuSO}_{4} \cdot 5 \mathrm{H}_{2} \mathrm{O}$ & 0.03 & 0.03 \\
\hline $\mathrm{Kl}$ & 0.01 & 0.01 \\
\hline
\end{tabular}

*It adjusts to $100 \mathrm{~g}$ with the cellulose

Body weight

During the experimental period, body weight was recorded once a week.

Bone density, cross-sectional area and bone mineral content

For the pQCT (XCT Research SA model. StratecMedizintechnik GmbH, Pfozheim, Germany) examinations, the bone samples were centrally located between the source of the scanner unit and detector with the aid of a support. To procuce a scout-view that was an image of the bone slice, the tomographic scan was displayed on the screen (Fig. 1). The mandibular bone was scanned around the center of the mandibular first molar mesial root at 3 different positions with an interval of $0.1 \mathrm{rmm}$. The slices, which consisted of trabecular and cortical components, were measured with a voxel size of $0.08 \mathrm{~mm}$ and height of $0.26 \mathrm{~mm}$. Using this procedure, the
Table 3 Vitamin mixture of all diets

\begin{tabular}{lrc} 
Vitamin A·acetate & 50,000 & $\mathrm{IU}$ \\
Vitamin D3 & 10,000 & $\mathrm{IU}$ \\
Vitamin E·acetate & 500 & $\mathrm{mg}$ \\
Vitamin K3 & 520 & $\mathrm{mg}$ \\
Vitamin B1·hydrochloride & 120 & $\mathrm{mg}$ \\
Vitamin B2 & 400 & $\mathrm{mg}$ \\
Vitamin B6·hydrochloride & 80 & $\mathrm{mg}$ \\
Vitamin B12 & 0.05 & $\mathrm{mg}$ \\
Vitamin C & 3,000 & $\mathrm{mg}$ \\
D-biotin & 2 & $\mathrm{mg}$ \\
Folic acid & 20 & $\mathrm{mg}$ \\
Calcium pantothenate & 500 & $\mathrm{mg}$ \\
Para-aminobenzoic acid & 500 & $\mathrm{mg}$ \\
Niacin & 600 & $\mathrm{mg}$ \\
Inositol & 600 & $\mathrm{mg}$ \\
Corrin chloride & 20 & $\mathrm{~g}$ \\
\hline
\end{tabular}

${ }^{*}$ It adjusts to $100 \mathrm{~g}$ with the cellulose powder

cortical region was determined using cortical mode 1 at a threshold value of $690 \mathrm{mg} / \mathrm{cm}^{3}$, and then cortical bone density $\left(\mathrm{mg} / \mathrm{cm}^{3}\right)$, cortical bone cross-sectional area $\left(\mathrm{mm}^{2}\right)$, and cortical bone mineral content $(\mathrm{mg} / \mathrm{mm})$ were measured. In the same way, we measured trabecular bone density $\left(\mathrm{mg} / \mathrm{cm}^{3}\right)$, trabecular cross-sectional area $\left(\mathrm{mm}^{2}\right)$, and trabecular bone mineral content $(\mathrm{mg} / \mathrm{mm})$ using peel mode 2 at a threshold value of $395 \mathrm{mg} / \mathrm{cm}^{3}{ }^{16-18)}$.

Bone strength (non-invasive)

We also evaluated bone strength as a stress strain index (SSI) ${ }^{19-21)}$, which was determined using pQCT as a non-invasive assessment of mechanical properties at a threshold of $464 \mathrm{mg} / \mathrm{cm}^{3}$. This threshold value was determined to reduce a partial volume effect. The equation $\mathrm{SSI}=\mathrm{CBD} \cdot \mathrm{Z} / \mathrm{NCBD}$ (CBD: cortical bone density $\left(\mathrm{mg} / \mathrm{cm}^{3}\right)$, Z: section modulus $\left(\mathrm{mm}^{3}\right)$, NCBD: normal value of cortical bone density $1200 \mathrm{mg} / \mathrm{cm}^{3}$ ) 

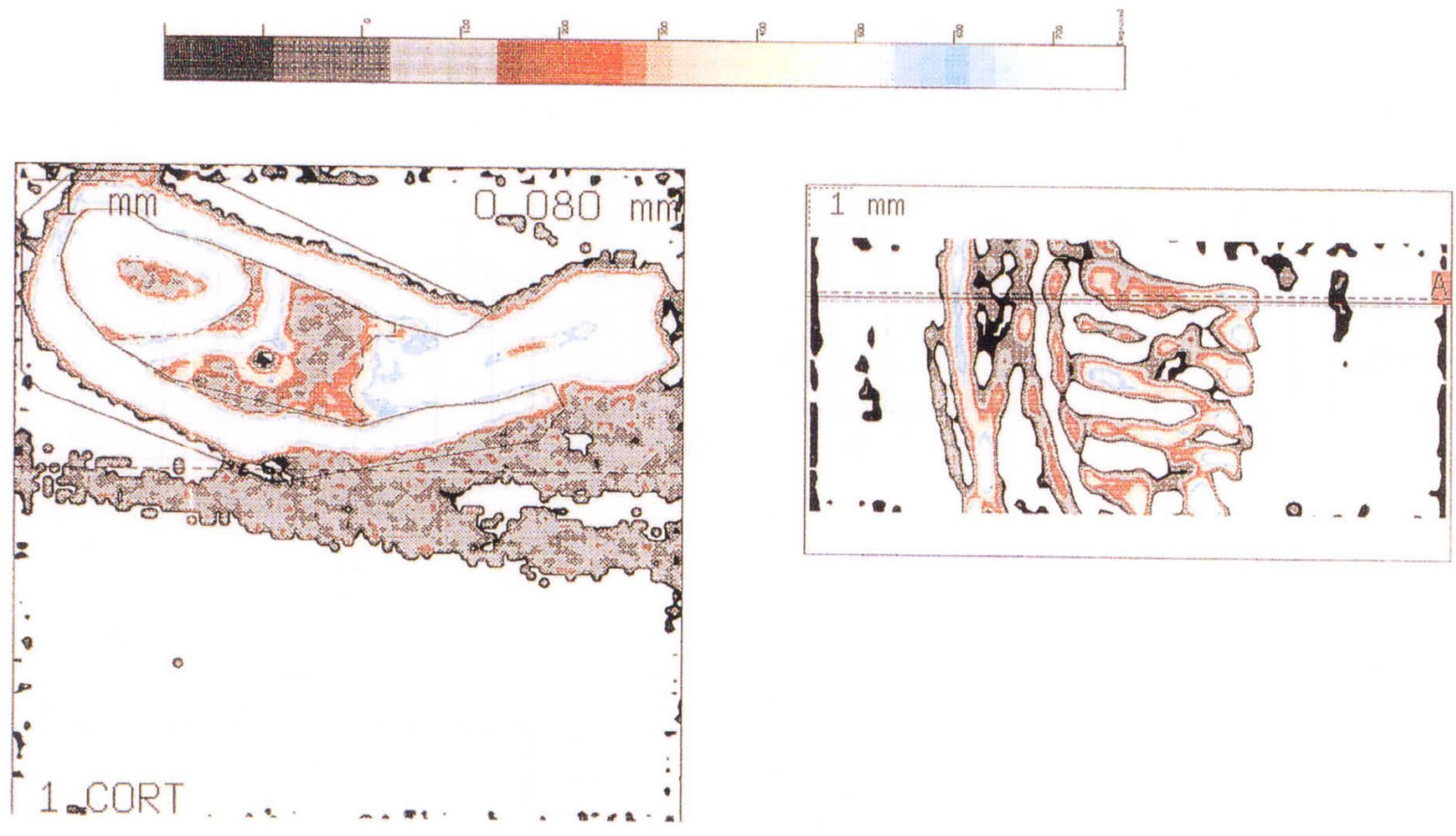

Fig. 1 pQCT slices. Left: Bone slice from tomographic scan. Right: Wister rat mandibular bones were scanned around the center of the mandibular first molar mesial root at 3 different positions with an interval of $0.1 \mathrm{~mm}$.

was used.

\section{Statistical analysis}

Data are expressed as the mean \pm SD for the effect of GSPE. Statistical differences were analyzed using an analysis of variance (ANOVA) at $\alpha=0.05$.

\section{RESULTS}

Body weight

At the beginning of the study, the initial body weights were $110.35 \pm 2.02 \mathrm{~g}, 111.26 \pm 2.07 \mathrm{~g}, 109.65 \pm$ $1.12 \mathrm{~g}$, and $114.66 \pm 5.07 \mathrm{~g}$ in Group A, B, C, and D, respectively. At the end of the 6-week experimental period the final body weights were $386.80 \pm 51.23 \mathrm{~g}$, $384.02 \pm 28.71 \mathrm{~g}, 390.33 \pm 16.35 \mathrm{~g}$, and $380.55 \pm 13.26 \mathrm{~g}$, respectively, in the 4 groups, which were not significantly different (Fig. 2).

Bone density, cross-sectional area, and mineral content

As for the cortical bone, bone density and the crosssectional area in Group D were significantly greater than in Group C $(p<0.05)$, while mineral content in Group D was also significantly higher than in Group C $(p<0.01)$. Further, the cross-sectional area in Group D was significantly larger than in Group A $(\mathrm{p}<0.05)$ (Fig. 3).

Regarding the trabecular bone, the crosssectional area and mineral content in Group D were significantly greater than in Group C $(p<0.05)$,

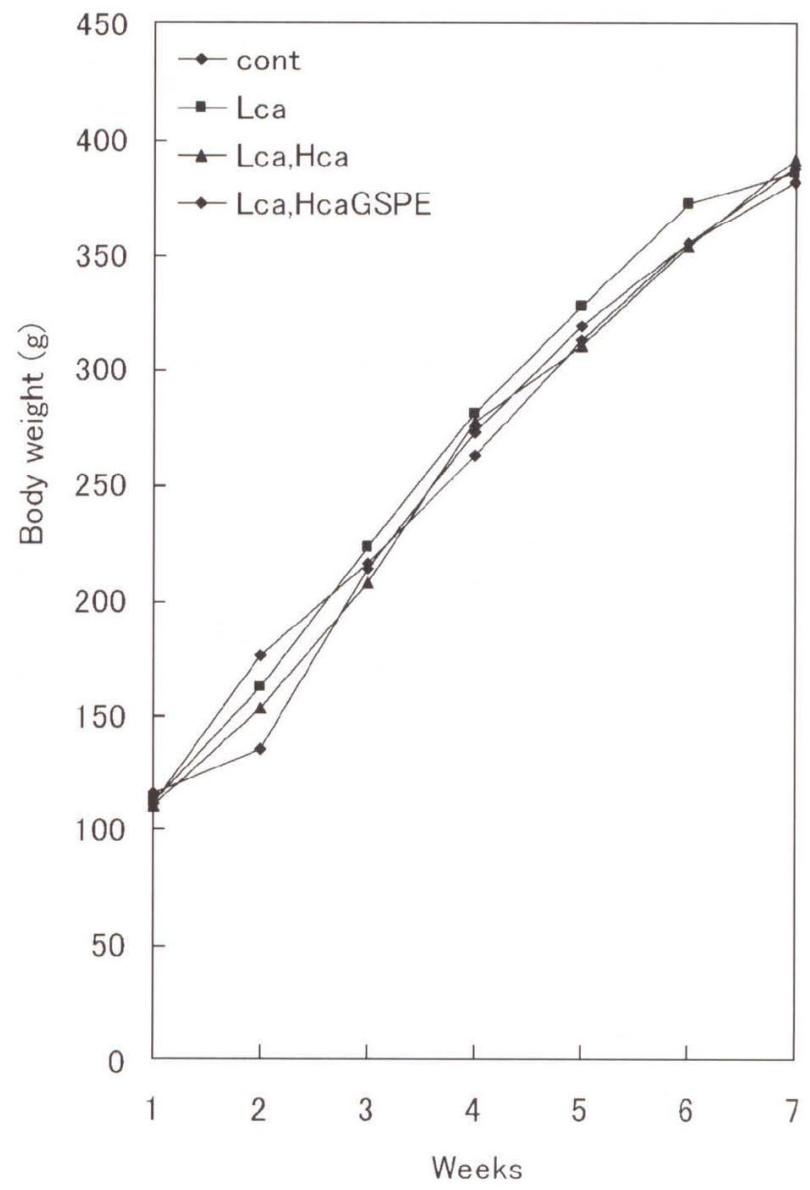

Fig. 2 Body weight of rats throughout the study period. 

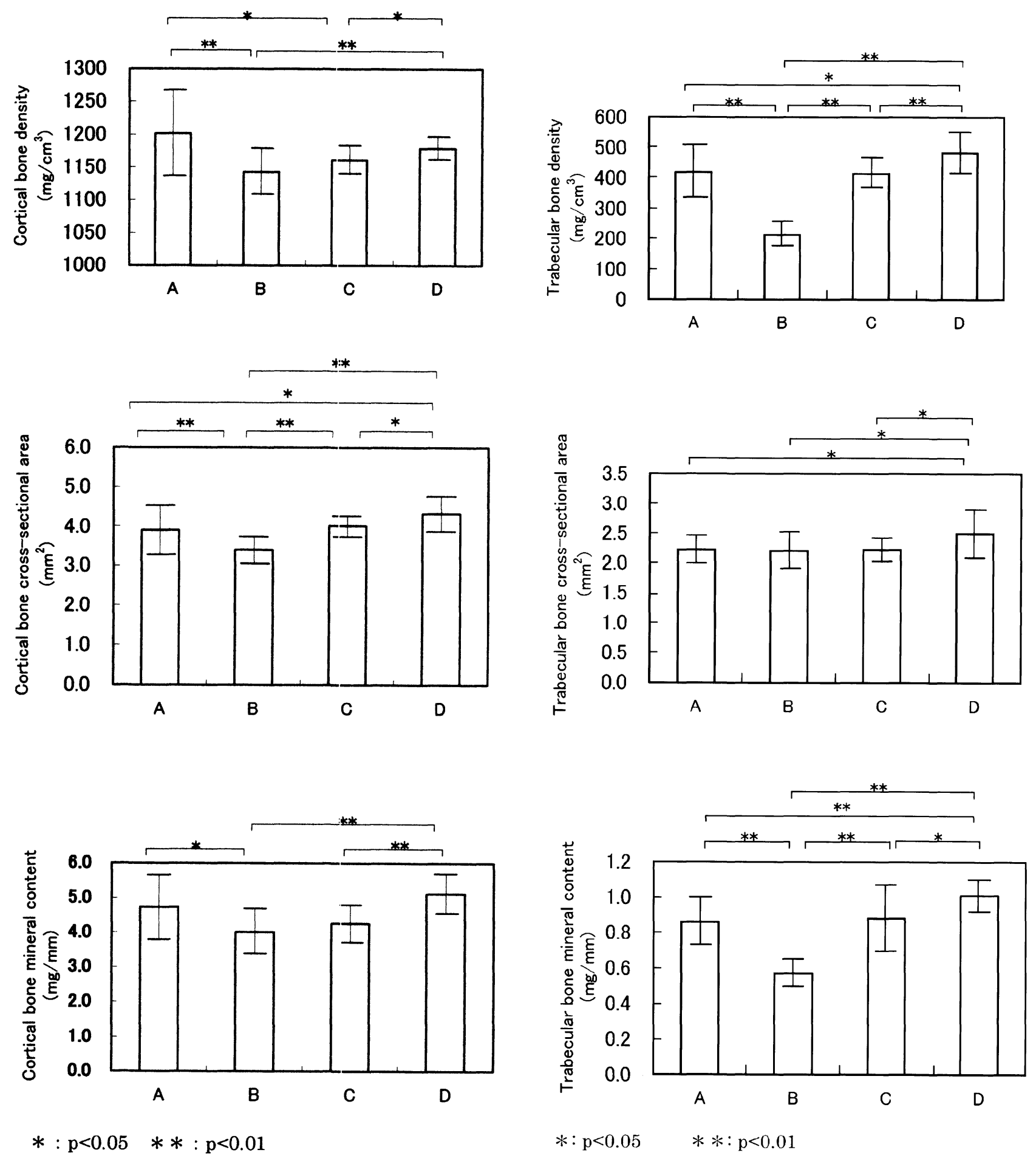

Fig. 3 Cortical bone density, cross-secticnal area, and mineral content.

Group A: standard diet

Group B: low-calcium diet

Group C: low-calcium/high-calcicm diet

Group D: low-calcium/high-calcicm diet with supplementary GSPE

Fig. 4 Trabecular bone density, cross-sectional area, and mineral content.

Group A: standard diet

Group B: low-calcium diet

Group C: low-calcium/high-calcium diet

Group D: low-calcium/high-calcium diet with supplementary GSPE 

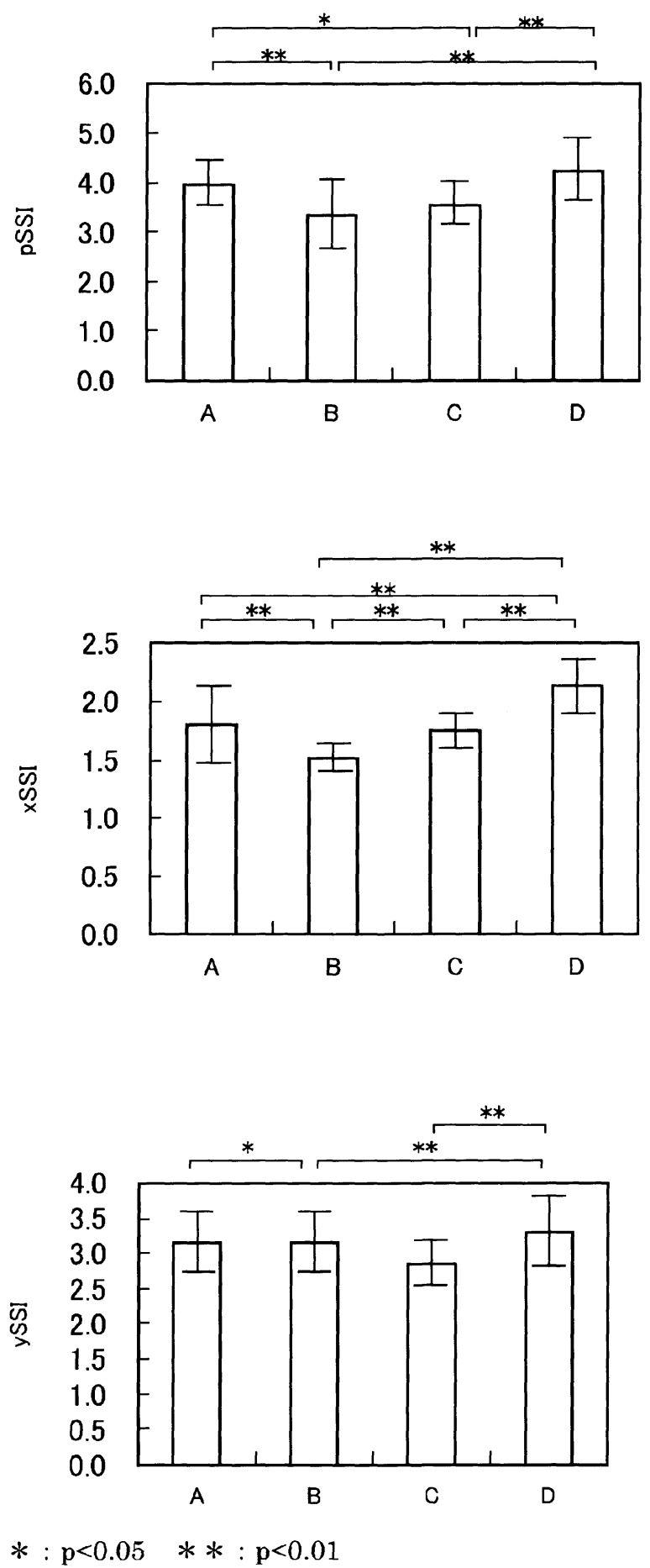

Fig. 5 Stress strain index (SSI).

Group A: standard diet

Group B: low-calcium diet

Group C: low-calcium/high-calcium diet

Group D: low-calcium/high-calcium diet with supplementary GSPE while bone density in Group D was also significantly higher than in Group C $(\mathrm{p}<0.01)$. Further, bone density and the cross-sectional area in Group $\mathrm{D}$ were significantly higher than in Group A $(p<0.05)$, while mineral content in Group D was also significantly higher than in Group A $(\mathrm{p}<0.01)$ (Fig. 4).

\section{Non-invasive bone strength}

SSI was demonstrated as the $\mathrm{x}$ (xSSI), y (ySSI), and z (pSSI) axes. xSSI, ySSI, and pSSI of Group D were significantly greater than those of Group C $(\mathrm{p}<0.05)$, and xSSI of Group D was significantly higher than that of Group A $(\mathrm{p}<0.05)$ (Fig. 5).

\section{DISCUSSION}

In recent years, with the rapid aging of Japanese society, concern regarding osteoporosis has increased, and the establishment of prevention and treatment modalities is considered to be a serious problem. Risk factors for the onset of osteoporosis are divided into internal factors such as hormones, aging, and genetic inheritance, and external factors including nutrition, exercise, and lifestyle. The former factors have a variety of congenital aspects, making adjustment difficult, however, the latter may be alterable by voluntary changes. The most important factor of osteoporosis development is bone density. Bone density is primarily a hereditary factor, however, it also can be influenced by nutrition and exercise. In adolescence, bone density reaches peak bone mass, and then it decreases in postmenopausal women and with aging in men. Prevention and treatment of osteoporosis is typically drug treatment and exercise therapy. As for drug therapy, high-calcium supplements, vitamin $\mathrm{D}$ metabolites, ipriflavone, bisphosphonates, calcitonin, estrogen, and combined therapy ${ }^{22-27)}$ are often given. However, these are symptomatic treatments and show various difficulties including degree of symptoms, patient basal disease, sensitivity to calcium or other drugs, and side effects.

In adolescence during the growth and development period, attempts have been made to prevent osteoporosis by increasing peak bone mass through the intake of calcium ${ }^{28-30)}$. Females see a rapid increase of bone density in the growth period, which typically occurs 2 to 3 years later in males. In adolescence, calcification of the bone is approximately 400-500 $\mathrm{mg}$ /day and calcium absorption is greater than $40 \%$ in the intestinum, therefore, calcium intake is important at this stage. However, current calcium intake by infants is lacking and chronic calcium deficiency is often encountered. Conventionally, calcium dietary therapy is directed against this condition ${ }^{1-4)}$. In our department, a significant effect was observed in a series of studies that used high levels calcium (UNICAL ${ }^{\circledR}$ ) to treat debilitated bones in $\operatorname{rats}^{31,32)}$. UNICAL calcium is a mixture of calcium carbonate 
and citrated calcium from sea urchin shells and is known to improve absorption by the intestinum from the addition of chondroitin sulfate and by refining the granularity ${ }^{33)}$. However, it is difficult to reach optimal bone mass values without continual calcium supplementation.

In the present study, we investigated the effects of GSPE with a high-calcium cliet. GSPE is a flavonoid with a vitis vinifera origin ${ }^{34)}$. Flavonoids are classified by their structure into 9 groups; flavones, flavonols, isoflavones, flavanes, catechins, flavanones, flavanonol, chalcones, and anthocyanin. The main ingredients of GSPE, Jroanthocyanidins, are a part of the catechins group and typically are condensed as tannin. They can be divided into procyanidins, prodelphinidins, and profisetinidins by the substitution form of hydroxyl on the basic frame, flavan-3-ols. Flavonoids have biological regulatory activities, such as antioxidant, anti-tumor, antihypertensive, and antidiabetic effect ${ }^{35-38)}$. As for the effect on bone, many reports have focused specifically on ipriflavone of the isoflavones group $^{5-9)}$. GSPE has variety of biological regulatory effects as do other flavonoids, however, its effect on bone has rarely been reported ${ }^{10-14)}$. We gave a high-calcium diet supplemented with GSPE to rats that had debilitated bones as the result of a previous low-calcium diet. We studied on dietetic treatment in rats during the growth and development period, so we used male rats to avoid a factor of hormones such as estrogen.

Of the methods, dual energy X-ray absorptiometry (DXA) has come to be known as the standard $^{39-41)}$. However, DXA expresses bone density as the area $\left(\mathrm{g} / \mathrm{cm}^{2}\right)$ because it only obtains twodimensional information about the bone. On the other hand, bone density determination by pQCT enables the measurement of density per unit volume. Using a mechanical analysis of mandibles in the growth period with $\mathrm{pQCT}$, we made a more accurate analysis. Further, we were able to separately measure cortical and trabecular bone, as well as determine SSI from a non-invasive mechanical analysis of cortical bone density and modulus of section. As a result, we were able to measure mandibles in a quantitative fashion.

As for cortical bone density, Group D had significantly greater bone density than Group C. Strength of the cortical bone and Young's modulus depends on cortical bone density ${ }^{42)}$, therefore, an increase of density results in an increase of bone strength, which was also shown in our SSI results. SSI is a reliable measurement, because it showed a high correlation $(r=0.94)^{43)}$ in comparison to a threepoint bending test of rat femurs.

Trabecular bone has an 8-10 times greater amount of metabolization as cortical bone, and has been used as an indicator of the reaction of bone to aging and medication ${ }^{44)}$. The trabecular bone density in Group D was high, showing that GSPE had a pronounced effect on the rat bones. Surprisingly, trabecular bone density in Group D was higher than that in Group A, which we considered to be a result of a temporary improvement in calcium absorptive ability in the bone. Cortical and trabecular crosssectional areas in Group D were increased more than in the other groups. Therefore, we concluded that GSPE significantly improved bone growth, because the bone cross-sectional area increases earlier than bone mineral content in childhood ${ }^{45)}$. By $0.003 \%$ of just a little GSPE, Group D showed significantly improved bone growth compared with Group C. It has been reported that ipriflavone inhibits bone resorption by an effect on osteoclasts ${ }^{46,47)}$ and hastens bone osteogenesis by an effect on osteoblasts ${ }^{48,49}$, however, it is not clear how GSPE acts on bone. In future, we hope to report its action mechanism from in vitro results, as basic research with osteoporosis of the mandibula is not enough on account of the fact that it is not clearly seen as a symptom of bone fracture and can not be compared with other types of bone.

Osteoporosis increases the risk of periodontal disease, and bone loss in the mandible has an influence on denture stability, as well as the application and prognosis of implants. It is considered that an increase in peak bone mass by the intake of calcium during the growth period, as well as diagnosis by quantitative and non-invasive estimation using pQCT, is also highly significant for the mandible.

\section{ACKNOWLEDGEMENTS}

We are pleased to acknowledge the considerable assistance of Mr. Kiichi Nonaka (ELK Corporation Co., Tokyo, Japan).

\section{REFERENCES}

1) Lau EM, Woo J, Lam V, Hong A. Milk supplementation of the diet of postmenopausal Chinese women on a low calcium intake retards bone loss. J Bone Miner Res 2001; 16(9): 1704-1709.

2) Dibba B, Prentice A, Ceesay M, Stirling DM, Cole TJ, Poskitt EM. Effect of supplementation on bone mineral accretion in Gambian children accustomed to a lowcalcium diet. Am J Clin Nutr 2000; 71(2): 544-549.

3) Ricci TA, Chowdhury HA, Heymsfield SB, Stahl T, Pierson RN Jr, Shapses SA. Calcium supplementation suppresses bone turnover during weight reduction in postmenopausal women. J Bone Miner Res 1998; 13(6): 1045-1050.

4) Need AG, Horowitz M, Morris HA, Nodin BE. Effect of three different calcium preparations on urinary calcium and hydroxyproline excretion in postmenopausal osteoporotic women. Eur J Clin Nutr 1991; 45(7): 357361. 
5) Katase K, Kato T, Hirai Y, Hasumi K, Chen JT. Effect of Ipriflavone on bone loss following a bilateral ovariectomy and menopause: a randomized placebocontrolled study. Calcif Tissue Int 2001; 69(2): 73-77.

6) Alexandersen P, Toussaint A, Christiansen C, Devogelaer JP, Roux C, Fechtenbaum J, Gennari C, Reginster JY. Ipriflavone in the treatment of postmenopausal osteoporosis: a randomized controlled trial. JAMA 2001; 285(11): 1482-1488.

7) Halpner AD, Kellermann G, Ahlgrimm MJ, Arndt CL, Shaikh NA, Hargrave JJ, Tallas PG. The effect of an Ipriflavone-containing supplement on urinary N-linked telopeptide levels in postmenopausal women. J Womens Health Gend Based Med 2000; 9(9): 995-998.

8) Fujita T, Fujii Y, Miyauchi A, Takagi Y. Comparison of antiresorptive activities of Ipriflavone, an isoflavone derivative, and elcatonin, an eel carbocalcitonin. J Bone Miner Metab 1999; 17(4): 289-295.

9) Gennari C, Agnusdei D, Crepaldi G, Isaia G, Mazzuoli G, Ortolani S, Bufalino L, Passeri M. Effect of Ipriflavone - a synthetic derivative of natural isoflavones - on bone mass loss in the early years after menopause. Menopause 1998; 5(1): 9-15.

10) Vinson JA, Mandarano MA, Shuta DL, Bagchi M, Bagchi D. Beneficial effects of a novel IH636 grape seed proanthocyanidin extract and a niacin-bound chromium in a hamster atherosclerosis model. Mol Cell Biochem 2002; 240(1-2): 99-103.

11) Ye X, Krohn RL, Liu W, Joshi SS, Kuszynski CA, McGinn TR, Bagchi M, Preuss HG, Stohs SJ, Bagchi D. The cytotoxic effects of a novel IH636 grape seed proanthocyanidin extract on cultured human cancer cells. Mol Cell Biochem 1999; 196(1-2): 99-108.

12) Bagchi D, Sen CK, Ray SD, Das DK, Bagchi M, Preuss HG, Vinson JA. Molecular mechanisms of cardioprotection by a novel grape seed proanthocyanidin extract. Mutat Res 2003; 523-524: 87-97.

13) Khanna S, Venojarvi M, Roy S, Sharma N, Trikha O, Bagchi D, Bagchi M, Sen CK. Dermal wound healing properties of redox-active grape seed proanthocyanidins. Free Radic Biol Med 2002; 33(8): 1089-1096.

14) Greul AK, Grundmann JU, Heinrich F, Pfitzner I, Bernhardt J, Ambach A, Biesalski HK, Gollnick H. Photoprotection of UV-irradiated human skin: an antioxidative combination of vitamin $\mathrm{E}$ and $\mathrm{C}$, carotenoids, selenium and proanthocyanidins. Skin Pharmacol Apple Skin Physiol 2002; 15(5): 307-315.

15) Qin $M$, Zhang $Z$, Maki $K$, Naito $M$, Morimoto A, Kimura M. The effect of calcium supplement given with a mixture of calcium carbonate and calcium citrate on the mandibular alveolar bone of pubertal rats. J Bone Miner Metab 1998; 16: 88-95.

16) Gasser JA. Assessing bone quantity by pQCT. Bone 1995; 17 (4 Suppl): 145S-154S.

17) Ferretti JL. Perspectives of pQCT technology associated to biomechanical studies in skeletal research employing rat models. Bone 1995; 17 (4 Suppl): 353S-364S.

18) Augat $\mathrm{P}$, Gordon CL, Lang $\mathrm{TF}$, Iida $\mathrm{H}$, Genant $\mathrm{HK}$. Accuracy of cortical and trabecular bone measurements with peripheral quantitative computed tomography
(pQCT). Pys Med Biol 1998; 43(10): 2873-2883.

19) Horikoshi $T$, Endo $N$, Uchiyama $T$, Tanizawa $T$, Takahashi HE. Peripheral quantitative computed tomography of the femoral neck in 60 Japanese women. Calcif Tissue Int 1999; 65(6): 447-453.

20) Iida H, Fukuda S. Age-related changes in bone mineral density, cross-sectional area and strength at different skeletal sites in male rats. $J$ Vet Med 2002; 64(1): 2934 .

21) Lind PM, Lind L, Larsson S, Orberg J. Torsional testing and peripheral quantitative computed tomography in rat humerus. Bone 2001; 29(3): 265-270.

22) Malabanan AO, Holick MF. Vitamin D and bone health in postmenopausal women. $\mathrm{J}$ Womens Health (Larchmt) 2003; 12(2): 151-156.

23) Heaney RP, Weaver CM. Calcium and vitamin D. Endocrinol Metab Clin North Am 2003; 32(1): 181-194.

24) Papapoulos SE. Ibandronate: a potent new bisphosphonate in the management of postmenopausal osteoporosis. Int J Clin Pract 2003; 57(5): 417-422.

25) Haskell SG. Selective estrogen receptor modulators. South Med J 2003; 96(5): 469-476.

26) Gur A, Denli A, Nas K, Cevik R, Karakoc M, Sarac AJ, Erdogan F. Possible pathogenetic role of new cytokines in postmenopausal osteoporosis and changes during calcitonin plus calcium therapy. Rheumatol Int 2002; $22(5)$ : 194-198.

27) Kitatani K, Morii H. Ipriflavone. Nippon Rinsho 1998; 56(6): 1537-1543.

28) Javaid MK, Cooper C. Prenatal and childhood influences on osteoporosis. Best Pract Res Clin Endocrinol Metab 2002; 16(2): 349-367.

29) Bailey DA, Martin AD, McKay HA, Whiting S, Mirwald R. Calcium accretion in girls and boys during puberty: a longitudinal analysis. $J$ Bone Miner Res 2000; 15(11): 2245-2250.

30) Teegarden D, Proulx WR, Martin BR, Zhao J, McCabe GP, Lyle RM, Peacock M, Slemenda C, Johnston CC, Weaver CM. Peak bone mass in young women. J Bone Miner Res 1995; $10(5)$ : 711-715.

31) Usijima S, Maki K, Xia B, Wang J, Kimura M. An experimental study on the effect of UNICAL ${ }^{\circledR}$ on Debilitated mandibles of rats in growth stage-using indicators of bone density and cephalometric analysis-. Pediatric Dental Journal 2003; 13(1): 29-35.

32) Qin M, Maki K, Dai W, Imamura T, Kimura M, Shi G. The effect of calcium supplement - UNICAL - a calcium citrate combined with IAM on the ultrastructural alteration of mandibular condyle of weanling rats. Pediatric Dental Journal 2000; 10(1): 93-102.

33) Zhang ZY, Dai WY, Maki K, Yasui H, Ueda K, Haruoka M, Kimura M. Aluminum equivalent densitometric study of the effect of a calcium supplement - UNICAL - a calcium citrate combined with IAM on bone loss in rats of adolescence. Pediatric Dental Journal 1999; 9(1): 99-102.

34) Brouillard R, George F, Fougerousse A. Polyphenols produced during red Wine ageing. Biofactors 1997; 6(4): 403-410.

35) Murota K, Terao J. Antioxidative flavonoid quercetin: 
implication of its intestinal absorption and metabolism. Arch Biochem Biophys 2003; 417 (1): 12-17.

36) Frydoonfar HR, McGrath DR, Spigelman AD. The variable effect on proliferation o: a colon cancer cell line by the citrus fruit flavonoid Naringenin. Colorectal Dis 2003; 5(2): 149-152.

37) Jouad H, Lacaille-Dubois MA, Lyoussi B, Eddouks M. Effects of flavonoids extracted from Spergularia purpurea Pers. on arterial blood pressure and renal function in normal and hypertensive rats. $J$ Ethnopharmacol 2001; 76(2): 159-163.

38) Rizvi SI, Zaid MA. Insulin-like effect of (-) epicatechin on erythrocyte membrane acetylcholinesterase activity in type 2 diabetes mellitus. Clin Exp Pharmacol Physiol 2001; 28(9): 776-778.

39) Sato M, McClintock C, Kim J, Turner CH, Bryant $\mathrm{HU}$, Magee D, Slemenda CW. Dual-energy x-ray absorptiometry of raloxifene effects on the lumbar vertebrae and femora of ovariectomized rats. J Bone Miner Res 1994; 9(5): 715-724.

40) Rosen HN, Tollin S, Balena R. Middlebrooks VL, Beamer WG, Donohue LR, Rosen C, Turner A, Holick M, Greenspan SL. Differentiating between orchiectomized rats and controls using measurements of trabecular bone density: a comparison among computerized tomography. Calcif Tissue Int 1995; 57(1): 35-39.

41) Horton JA, Murray GM, Spadaro JA, Margulies BS, Allen MJ, Damron TA. Precision and accuracy of DXA and pQCT for densitometry of the rat femur. $J$ Clin Densitom 2003; 6(4): 381-390.

42) Carter DR, Hayes WC. Bone compressive strength: the influence of density and strain rate. Science 1976; 194(4270): 1174-1176.

43) Ferretti JL, Capozza RF, Zanchetta JR. Mechanical validation of a tomographic ( $\mathrm{pQCT}$ ) index for noninvasive estimation of rat femur bending strength. Bone 1996; 18(2): 97-102.

44) Schneider PF, Fischer M, Allolio B, Felsenberg D, Schroder U, Semler J, Ittner JR. Alendronate increases bone density and bone strength at the distal radius in postmenopausal women. J Bone Miner Res 1999; 14(8): 1387-1393.

45) Molgaard C, Thomsen BL, Michaelsen KF. Whole body bone mineral accretion in healthy children and adolescents. Arch Dis Child 1999; 81(1): 10-15.

46) Miyauchi A, Notoya K, Taketomi S, Takagi Y, Fujii Y, Jinnai K, Takahasi K, Chihara K, Fujita T. novel Ipriflavone receptors coupled to calcium influx regulate osteoclast differentiation and function. Endocrinology 1996; 137 (8): 3544-3550.

47) Petilli M, Fiorelli G, Benvenuti S, Frediani U, Gori F, Brandi ML. Interaction between Ipriflavone and the estrogen receptor. Calcif Tissue Int 1995; 56(2): 160-165.

48) Hagiwara $H$, Naruse $M$, Adachi $C$, Inoue A, Hiruma Y, Otska E, Naruse K, Demura H, Hirose S. Ipriflavone down-regulates endothelin receptor levels during differentiation of rat calvarial osteoblast-like cells. J Biochem (Tokyo) 1999; 126(1): 168-173.

49) Civitelli R. In vitro and in vivo effects of Ipriflavone on bone formation and bone biomechanics. Calcif Tissue Int $1997 ; 61(1): 12-14$. 